\title{
GOBIERNO CORPORATIVO Y SUPERVIVENCIA EMPRESARIAL EN ÉPOCA DEL COVID-19
}

\section{CORPORATE GOVERNANCE AND BUSINESS SURVIVAL IN THE TIME OF COVID-19}

\author{
ALBERTO J. TAPIA HERMIDA* \\ Fecha de recepción: 9 de octubre 2020 \\ Fecha de aceptación 20 de noviembre 2020 \\ Disponible en línea: 30 de diciembre 2020 \\ Para citar este artículo/To cite this article
}

TAPIA Hermida, Alberto J. Gobierno corporativo y supervivencia empresarial en época del COVID-19, 53 Rev.Ibero-Latinoam.Seguros, 317-336 (2020). https://doi.org/10.11144/ Javeriana.ris53.gcse

doi:10.11144/Javeriana.ris53.gcse

\footnotetext{
" Licenciado en Derecho por la Universidad Autónoma de Madrid. Doctor en Derecho por la Universidad Complutense de Madrid. Es Abogado de ESTUDIO JURÍDICO SÁNCHEZ CALERO. Ha sido Letrado de la Comisión Nacional del Mercado de Valores. Es experto en Derecho de seguros y ha intervenido en numerosos litigios relativos a este sector. También tiene una dilatada experiencia en mercados financieros y en Derecho bancario y bursátil. Emite dictámenes e informes en asuntos mercantiles y ha sido requerido para actuar como experto en procedimientos judiciales y arbitrales. Catedrático Acreditado de Derecho mercantil. Facultad de Derecho. Universidad Complutense de Madrid. Contacto: atapia@sanchezcalero. com; Orcid: https://orcid.org/0000-0002-5736-1611.
} 


\section{RESUMEN}

Este estudio comienza analizando la influencia de la pandemia del COVID-19 como origen de la gran crisis económica del siglo XXI y como acelerador dramático de las tendencias principales de la regulación mercantil y financiera. Después, su segunda parte examina la regulación del gobierno corporativo en España en época del COVID-19 analizando las tendencias generales y la normativa extraordinaria sobre los órganos de gobierno de las sociedades mercantiles en general y de las sociedades anónimas cotizadas en particular. Además, examina la normativa extraordinaria sobre las cuentas de las sociedades mercantiles y otras medidas extraordinarias que repercuten en el Derecho societario. La tercera parte del estudio analiza las medidas para facilitar la supervivencia empresarial en España en época del COVID-19, tanto en sentido funcional, con las medidas concursales y societarias, como estructural o institucional, con la creación del Fondo Apoyo a la Solvencia de Empresas Estratégicas (FASEE).

Palabras clave: COVID-19, gobierno corporativo, sociedades mercantiles, sociedades anónimas cotizadas, supervivencia empresarial, medidas concursales y societarias, Fondo Apoyo a la Solvencia de Empresas Estratégicas (FASEE).

\section{ABSTRACT}

This study begins by analyzing the influence of the COVID-19 pandemic as the origin of the great economic crisis of the 21st century and as a dramatic accelerator of the main trends in commercial and financial regulation. Then, its second part examines the regulation of corporate governance in Spain at the time of COVID-19, analyzing the general trends and extraordinary regulations on the governing bodies of commercial companies in general and of listed public limited companies in particular. In addition, it examines the extraordinary regulations on the accounts of commercial companies and other extraordinary measures that have an impact on corporate law. The third part of the study analyzes the measures to facilitate business survival in Spain at the time of COVID-19, both in a functional sense, with insolvency and corporate measures, as well as structural or institutional, with the creation of the Support Fund for the Solvency of Strategic Companies (FASEE).

Keywords: COVID-19, corporate governance, mercantile companies, listed companies, business survival, bankruptcy and corporate measures, Support Fund for the Solvency of Strategic Companies (FASEE). 


\section{SUMARIO}

Presentación: gratitud e íntima conexión de este estudio con el seguro. I. Introducción: la pandemia delCOVID-19 como origen de la gran crisis económica del siglo XXI y como acelerador dramático de las tendencias principales de la regulación mercantil y financiera. A) La pandemia del COVID-19 como origen de la gran crisis económica del siglo XXI. B) La pandemia del COVID-19 como acelerador dramático de las tendencias principales de la regulación mercantil y financiera. 1. Aceleración de la sostenibilidad financiera. 2. Aceleración de la digitalización financiera. 3. Aceleración de la concentración financiera. II. Gobierno corporativo en España en época del COVID-19. A) Tendencias generales. 1. Aceleración de la digitalización societaria. 2. Tipos de disposiciones que integran la normativa excepcional promulgada para combatir las consecuencias del impacto de la pandemia del COVID-19 en las sociedades. 3. Ámbitos de aplicación. B) Normativa extraordinaria sobre los órganos de gobierno de las sociedades mercantiles en general. 1. La convocatoria y la celebración de la junta general. 2. Las sesiones de los órganos de gobierno de las sociedades mercantiles. 3. Los acuerdos de los órganos de gobierno de las sociedades mercantiles. C) Normativa extraordinaria sobre los órganos de gobierno de las sociedades anónimas cotizadas. 1. Juntas generales. 2. Consejos de Administración. D) Normativa extraordinaria sobre las cuentas de las sociedades mercantiles. 1. El proceso de elaboración de las cuentas. 2. La propuesta de aplicación del resultado. 3. La información financiera periódica de las sociedades cotizadas. E) Otras medidas extraordinarias que repercuten en el Derecho societario. 1. La suspensión del ejercicio del derecho de separación en las sociedades de capital. 2. La suspensión del reintegro de las aportaciones en las sociedades cooperativas. III. Supervivencia empresarial en España en época del COVID-19. A) La normativa extraordinaria promulgada en España para facilitar la supervivencia empresarial en época del COVID-19: doble alcance funcional y estructural. B) Normativa extraordinaria funcional: las medidas concursales y societarias. C) Normativa extraordinaria estructural o institucional: el Fondo Apoyo a la Solvencia de Empresas Estratégicas (FASEE). 1. La estructura del FASEE. 2. El funcionamiento del FASEE. 


\section{PRESENTACIÓN: GRATITUD E ÍNTIMA CONEXIÓN DE ESTE ESTUDIO CON EL SEGURO}

Sirvan estas primeras líneas de mi estudio para agradecer -en la persona del prestigioso profesor y querido amigo de quien suscribe, Carlos Ignacio JARAMILLO- la hospitalidad editorial que me brinda, una vez más, esta Revista Ibero-Latinoamericana de Seguros, en cuyo número 52 de este año 2020, tuve la oportunidad de publicar mi estudio sobre "Las medidas extraordinarias adoptadas en España y Europa en los seguros y en los planes de pensiones para combatir las consecuencias de la pandemia del COVID-19" en España. Regreso al abrigo de la Pontificia Universidad Javeriana de Colombia para ofrecer este nuevo estudio sobre el "Gobierno corporativo y supervivencia empresarial en época del COVID-19" en España, con el deseo de que resulte útil a los países hermanos de Iberoamérica y compense, de este modo, al manifiesto abuso de la amistad de Carlos Ignacio JARAMILlo que públicamente confieso.

Una vez dicho lo anterior, nos parece imprescindible dejar sentado, desde el mismo principio de este estudio, las vinculaciones directas que tienen las cuestiones examinadas con el seguro, ya que no en vano estamos publicándolo en la Revista Ibero-Latinoamericana de Seguros. Pues bien, las conexiones con el seguro con los dos temas que analizamos son evidentes ${ }^{1}$ porque:

a) La normativa extraordinaria promulgada para adaptar las reglas generales del gobierno corporativo a la grave crisis causada por el COVID-19 tiene directa relación con los seguros de responsabilidad civil de administradores (D\&O) no sólo por incidencia de la pandemia en los deberes de diligencia de los administradores establecidos en la Ley de Sociedades de Capital; sino también por esa misma incidencia de la pandemia del COVID-19 en los deberes de los administradores en la situaciones de insolvencia de las sociedades que se multiplicarán en un futuro inminente y donde existe una normativa proteica y cambiante a la luz de la propia pandemia del COVID-19 en el ámbito concursal ${ }^{2}$.

b) La normativa extraordinaria promulgada para facilitar la supervivencia empresarial durante la grave crisis causada por el COVID-19 tiene directa relación tanto con los seguros de crédito en general y los seguro de crédito a la exportación en particular $^{3}$, ante la miríada de insolvencias empresariales que anuncia el futuro inmediato, tendrá una muy especial importancia; como en los seguros de pérdida de beneficios por

\footnotetext{
1 El lector interesado puede consultar la entrada de nuestro blog financiero (ajtapia.com) de 23 de septiembre de 2020 sobre "COVID 19 y seguros: diez preguntas sobre los contratos de seguro ante la pandemia del coronavirus. Webinar de SEAIDA conmemorativa del cuadragésimo aniversario de la Ley de Contrato de Seguro de 1980".

2 En este punto, nos remitimos a la entrada de nuestro blog financiero del 15 de septiembre de 2020 sobre "Una nueva Guía Concursal ante el tsunami empresarial que se avecina" en la que dábamos cuenta del nuevo Texto Refundido de la Ley Concursal (TRLC) vigente desde el pasado 1 de septiembre de 2020 y de la "Guía Concursal" que acabamos de publicar en la editorial Thomson Reuters Aranzadi, dentro de la "Colección de Guías Prácticas".

3 Sobre el seguro de crédito en general, puede verse nuestra Guía del Contrato de Seguro, Ed, Thomson Reuters Aranzadi, Cizur Menor 2018, pp. 114 y ss.
} 
interrupción de una empresa ${ }^{4}$ cuando esta quede paralizada, total o parcialmente, como consecuencia de los confinamientos derivados del combate contra el coronavirus.

\section{INTRODUCCIÓN: LA PANDEMIA DEL COVID-19 COMO ORIGEN DE LA GRAN CRISIS ECONÓMICA DEL SIGLO XXI Y COMO ACELERADOR DRAMÁTICO DE LAS TENDENCIAS PRINCIPALES DE LA REGULACIÓN MERCANTIL Y FINANCIERA}

\section{A) La pandemia del COVID-19 como origen de la gran crisis económica del siglo XXI}

Desde el mismo momento en el que la pandemia del Coronavirus o COVID-19 comenzó a extenderse, desde la China, por todo el Orbe, hemos sido plenamente conscientes de que el impacto dramático del coronavirus nos obligará a repensar el orden mundial y, en particular, la economía y, dentro ella, muy especialmente, el sistema financiero global. En concreto, este sistema financiero, con ocasión de la misteriosa -en su mismo origen- pandemia que estamos padeciendo, se ha revelado como el verdadero corazón de los sistemas productivos que precisan de la sangre de la liquidez para no morir de inanición y arrastrar, con ellos, al paro, a la miseria e incluso a la muerte a grandes capas de población, especialmente, a las clases populares que viven de su trabajo.

Este ejercicio de reflexión resulta particularmente necesario en España, vista la gravedad y profundidad de la crisis económica potenciada por una gestión política que nos está conduciendo a alcanzar -desgraciadamente para quienes lo habitamos-cotas de ineficiencia en lo sanitario y en lo económico que serán difícilmente compatibles, en un futuro inmediato, no solo con el Estado de bienestar del que disfrutamos en la actualidad, sino incluso con la paz social que se verá amenazada por porcentajes de paro insostenibles y anormales en el concierto de naciones desarrolladas en el que nos ubicamos (a estos efectos, nos remitimos a los pronósticos más recientes del Banco de España, el FMI, la OCDE y FUNCAS) ${ }^{5}$. En efecto, la crisis económica derivada de la pandemia del COVID-19 se agrava en nuestro país a resultas de una gestión nociva en lo sanitario y caótica en lo económico, con una normativa espasmódica de un marcado sesgo totalitario ${ }^{6}$.

\footnotetext{
4 Sobre este seguro de pérdida de beneficios por interrupción de empresa puede verse nuestra Guía del Contrato de Seguro, Ed, Thomson Reuters Aranzadi, Cizur Menor 2018, pp. 113 y ss.

5 Los recogíamos en la entrada de nuestro blog financiero (ajtapia.com) del pasado 15 de septiembre sobre "Una nueva Guía Concursal ante el tsunami empresarial que se avecina".

${ }^{6}$ La explicación técnico-jurídica de esta última afirmación la podrá encontrar el lector en la entrada de nuestro blog financiero de 31 de mayo de este infausto año 2020 titulada "Los Reales Decretos Leyes derivados de la crisis del COVID 19: De la extraordinaria y urgente necesidad constitucional a la ordinaria y recurrente fatalidad inconstitucional".
} 
Procede iniciar desde ya mismo esta reflexión porque es evidente que, desde su minuto cero, la pandemia del COVID-19 ha tenido efectos económicos directos en el mercado financiero bien sea en forma de hundimiento de las cotizaciones bursátiles, bien sea en forma de la necesaria restricción a las inversiones exteriores directas exigida por aquel hundimiento o bien sea en forma de la necesidad de habilitar avales públicos a los préstamos y créditos bancarios a las empresas golpeadas por la crisis ${ }^{7}$.

\section{B) La pandemia del COVID-19 como acelerador dramático de las tendencias principales de la regulación mercantil y financiera}

En esta reflexión sobre cómo será el mundo posterior a la pandemia del COVID-19 y, en particular, el sistema financiero cada vez más global; la atenta observación de la realidad nos ha venido a confirmar que la crisis causada por el COVID-19 ha operado como una suerte de acelerador -trágico- de tres tendencias que ya venían determinando el presente y determinarán -desde ahora y con mayor razón y urgencia- el futuro del mercado financiero: la sostenibilidad, la digitalización y la concentración societaria. Así, el COVID-19 - cual si fuera un acelerador de partículas como el Ciclotrónestá operando para acelerar estos tres vectores:

\section{Aceleración de la sostenibilidad financiera}

En primer lugar y en cuanto a la sostenibilidad se refiere, será imprescindible intensificar las iniciativas para hacer de nuestro Planeta un sistema humanamente sostenible. Y, para ello, deberá comenzar siendo sostenible la economía mundial y, en particular, el sistema financiero que la alimenta como verdadero corazón que insufla la liquidez precisa para su funcionamiento y selecciona las inversiones a las que se destina el ahorro ${ }^{8}$.

\section{Aceleración de la digitalización financiera}

En segundo lugar y en lo referente a la digitalización, en un mundo que ha obligado a confinar y alejar físicamente a unas personas de otras, la digitalización de nuestro ocio y de nuestro trabajo se impondrá como una auténtica "ley de hierro" que ha pasado de ser una oportunidad a una necesidad inaplazable. En particular, el mercado financiero operará básicamente a través de las tecnofinanzas (Fintech) y los tecnoseguros (Insurtech) ${ }^{9}$.

\footnotetext{
7 El lector puede consultar nuestro estudio sobre "El impacto en el sistema financiero de las medidas extraordinarias adoptadas para paliar las consecuencias económicas de la pandemia del COVID-19" publicado en la Revista de Derecho del Mercado de Valores, RMV n. ${ }^{\circ}$ 26, 2020.

${ }^{8}$ Sobre la sostenibilidad financiera, el lector interesado puede ver nuestro estudio sobre la "Sostenibilidad financiera en la UE: un salto cualitativo en su regulación mediante el Reglamento (UE) 2020/852 de 18 de junio de 2020 sobre inversiones sostenibles", publicado en el Diario La Ley, N 9672, Sección Tribuna, 13 de julio de 2020 .

9 Sobre la digitalización financiera en general y los tecnoseguros en particular, el lector puede ver nuestro estudio "Insurtech" en la obra colectiva "Revolución digital, Derecho mercantil y token economía".
} 


\section{Aceleración de la concentración financiera}

En tercer lugar y en cuanto afecta a la concentración societaria, la realidad más reciente nos muestra una nueva faceta del impacto de la pandemia del COVID-19 en el sistema financiero doméstico como acelerador de las concentraciones bancarias. En efecto, hablamos de "acelerador"-que no creador- de tendencias previamente existentes porque el paisaje del mercado bancario previo a que se desatara la pandemia del COVID-19 mostraba una tendencia clara hacia la reestructuración con la progresiva concentración de entidades de crédito. Tendencia a la concentración tanto más acusada cuanto menor fuera el tamaño del mercado bancario nacional y de los bancos que en él operaran. El mantenimiento de unos tipos de interés del dinero anormalmente bajos, cuando no negativos; la presión regulatoria; y la competencia de las nuevas entidades Fintech eran otros tantos factores que coadyuvaban a la concentración de bancos para crear otros cuyo superior tamaño les permitiera competir en el nuevo escenario global. Operaciones como la compra del Banco Popular por el Banco Santander ha sido un caso paradigmático de reestructuración y concentración de entidades de crédito en la época anterior a la pandemia ${ }^{10}$.

El primer caso paradigmático de reestructuración y concentración de entidades de crédito en Europa durante esta época infausta de la pandemia del COVID-19 que nos está tocando vivir es la absorción de BANKIA por CAIXABANK. Así, el pasado día 18 de septiembre de 2020, tanto BANKIA como CAIXABANK comunicaban a la CNMV sendas informaciones privilegiadas en las que comunicaban que sus Consejos de Administración habían acordado, en sus respectivas sesiones de 17 de septiembre aprobar y suscribir el proyecto común de fusión por absorción de BANKIA, S.A. (sociedad absorbida) por CAIXABANK (sociedad absorbente).

Decimos que esta operación de concentración bancaria es un producto típico de la pandemia del COVID-19 en el sentido de que obedece a dos tipos de causas concurrentes: Por una parte, las causas normales a este tipo de operaciones de concentración como pueden ser las sinergias verticales y horizontales que con ella se logran ${ }^{11}$. Por otro lado, las causas excepcionales o "pandémicas", como puede ser la protección a base de tamaño contra la morosidad futura que, sin duda, ocasionará esta pandemia ${ }^{12}$.

Muñoz PÉRez, A.F. (Dir.). De la Orden de la Cruz, C./ Martínez Laburta, C. (Coords,), Ed. Tecnos, Madrid 2019, pp. 544-559.

10 Sobre esta operación, el lector puede consultar nuestro estudio sobre "La crisis del Banco Popular: estado de la cuestión" publicado en el Libro Homenaje al Profesor Ubaldo Nieto de Alba, Volumen III. Estudios Jurídicos, Ed. Tirant lo Blanch. Valencia 2020, págs. 257-281 al que nos referimos en la entrada de nuestro blog del pasado 7 de julio de 2020 titulada "Conclusions (5): The Popular Bank crisis: state of the issue".

11 A estas causas normales y preexistentes se refiere la "justificación de la fusión" que se menciona en el apartado 1.1. Proyecto común de fusión de 17 de septiembre de 2020 cuando dice: "En los últimos años, el mercado está experimentando un proceso de reestructuración y progresiva concentración del sector bancario, derivado de la necesidad de las entidades bancarias de mejorar su eficiencia y optimizar sus costes operativos en un entorno de prolongada reducción del margen de intereses, como consecuencia de los tipos de interés negativos y del proceso de desapalancamiento de la economía".

12 A estas causas pandémicas y sobrevenidas se refiere la "justificación de la fusión" que se menciona en el apartado 1.1. Proyecto común de fusión de 17 de septiembre de 2020 cuando dice: "La situación actual 


\section{GOBIERNO CORPORATIVO EN ESPAÑA EN ÉPOCA DEL COVID-19}

\section{A) Tendencias generales}

\section{Aceleración de la digitalización societaria}

La pandemia generada por el COVID-19 ha operado como un acelerador trágico de la digitalización societaria que ya se había visto impulsada, en el ámbito de la UE, por la Directiva (UE) 2019/1151 del Parlamento Europeo y del Consejo, de 20 de junio de 2019, por la que se modifica la Directiva (UE) 2017/1132 en lo que respecta a la utilización de herramientas y procesos digitales en el ámbito del Derecho de sociedades.

\section{Tipos de disposiciones que integran la normativa excepcional promulgada para combatir las consecuencias del impacto de la pandemia del COVID-19 en las sociedades}

La regulación extraordinaria del gobierno corporativo de sociedades en tiempos de coronavirus está integrada por dos tipos de normas ${ }^{13}$ :

a) En primer lugar, por normas legales en sentido estricto (hard law) establecidas en el RDL 8/2020 -modificado por la disposición final primera del RDL 11/2020que adoptó un conjunto de medidas extraordinarias aplicables al funcionamiento de los órganos de gobierno de las asociaciones, las sociedades civiles y mercantiles, las sociedades cooperativas y las fundaciones (art. 40); y de las sociedades anónimas cotizadas (art. 41).

b) En segundo lugar, por Comunicados de las autoridades supervisoras (soft law) que son: El Comunicado de la CNMV de 10 de marzo de 2020 sobre "Consideraciones de la CNMV sobre las Juntas Generales de las sociedades cotizadas ante la situación creada por el COVID-19"14; y el Comunicado conjunto complementario del Colegio de Registradores de España y la CNMV 28 de abril de 2020 sobre las juntas

\footnotetext{
derivada de la pandemia mundial causada por la COVID-19, aunque ha reafirmado la función fundamental de las entidades bancarias como soporte de las familias y de las empresas, que en muchos casos han visto recortadas de forma drástica sus fuentes de ingresos, tendrá como consecuencia que los tipos de interés permanezcan en niveles muy bajos o, incluso, negativos durante un periodo más prolongado de lo esperado, al tiempo que supondrá un incremento de la morosidad y de las dotaciones por este concepto, poniendo presión sobre la rentabilidad de las entidades. Este contexto determina la necesidad de buscar una mayor escala en el sector bancario".

${ }_{13}$ El lector interesado en profundizar en la normativa excepcional promulgada en España para combatir las consecuencias del impacto de la pandemia del COVID 19 en las sociedades puede ver nuestro estudio sobre "Gobierno corporativo de sociedades cotizadas en tiempos de coronavirus. Las medidas extraordinarias de funcionamiento de los órganos de gobierno de las sociedades anónimas cotizadas adoptadas ante la pandemia del COVID 19"; publicado en la Revista de Derecho de Sociedades n. ${ }^{\circ} 59$ (2020), págs. 21 a 44. ${ }^{14}$ V. la entrada de nuestro blog financiero (ajtapia.com) de 13.03.2020 sobre "El impacto del coronavirus en los mercados financieros: Comunicados de ESMA y de la CNMV".
} 
generales de sociedades cotizadas convocadas para su celebración mientras estén en vigor restricciones o recomendaciones derivadas de la crisis sanitaria. A estos dos comunicados habría que añadir el Comunicado de ESMA de 11 de marzo de $2020^{15}$.

\section{3. Ámbitos de aplicación}

El Real Decreto-Ley $N^{\circ} 8 / 2020$, de 17 de marzo, de medidas urgentes extraordinarias para hacer frente al impacto económico y social del COVID-19 (RDL 8/2020) adoptó un conjunto de medidas extraordinarias aplicables al funcionamiento de los órganos de gobierno de entidades privadas ${ }^{16}$ que afectaban, en particular, a dos tipos de entidades:

a) En primer lugar, a las personas jurídicas de Derecho privado, incluyendo las asociaciones, las sociedades civiles y mercantiles, las sociedades cooperativas y las fundaciones (art. 40).

b) En segundo lugar, a las sociedades anónimas cotizadas (art. 41). Esto es, al funcionamiento de los órganos de gobierno de las sociedades con valores admitidos a negociación en un mercado regulado de la Unión Europea.

Esta regulación societaria de carácter extraordinario establecida en el RDL 8/2020 ha sido objeto de dos modificaciones sucesivas sustanciales ${ }^{17}$ :

La primera por el Real Decreto-Ley $\mathrm{N}^{\circ} 11 / 2020$, de 31 de marzo, por el que se adoptan medidas urgentes complementarias en el ámbito social y económico para hacer frente al COVID-19 (RDL 11/2020) ${ }^{18}$ cuya disposición final primera modificó los arts. 40 y 41 del RDL 8/2020.

La segunda, por el Real Decreto-Ley N 19/2020, de 26 de mayo, por el que se adoptan medidas complementarias en materia agraria, científica, económica, de empleo y

\footnotetext{
15 En este sentido, cabe destacar que, en la medida en la que las sociedades anónimas participan en el mercado de valores como emisores, se ven concernidas por algunas de las recomendaciones contenidas en el Comunicado publicado por la Autoridad Europea de Valores y Mercados (ESMA, por sus siglas en inglés) el pasado 11 de marzo de 2020 sobre "Recomendaciones de ESMA a los participantes del mercado ante el impacto del COVID-19" (ESMA71-99-1289). En concreto, por las siguientes: a) Difusión de información al mercado - Los emisores de valores deben difundir sin demora cualquier información significativa sobre el impacto del COVID-19 en sus magnitudes económicas fundamentales, perspectivas o situación financiera, teniendo en cuenta las obligaciones de transparencia recogidas en el Reglamento de Abuso de Mercado; b) Información financiera - Los emisores de valores deben informar con transparencia sobre los actuales y los potenciales impactos del COVID-19 en su informe anual correspondiente a 2019 si aún no se ha formulado o, en caso contrario, en sus informaciones periódicas intermedias, en la medida de lo posible basándose en un análisis tanto cualitativo como cuantitativo de la actividad de sus negocios, situación financiera y rendimiento económico.

16 V., por todos, Peinado Gracia, J.I. “Derecho de sociedades no analógico (Reflexiones sobre las medidas de excepción en materia de sociedades mercantiles)”, La Ley Mercantil, N 69, 2020 (LA LEY 6409/2020). También puede ser útil ver la entrada de nuestro blog del 19 de marzo de 2020 sobre "Aspectos financieros y mercantiles de las medidas urgentes extraordinarias del Real Decreto-ley 8/2020 por el coronavirus (2)".

17 Sobre la extremada variabilidad de esta normativa nos hemos pronunciado en la entrada de nuestro blog de 31-05.2020 sobre "Los Reales Decretos Leyes derivados de la crisis del COVID-19: De la extraordinaria y urgente necesidad constitucional a la ordinaria y recurrente fatalidad inconstitucional".

18 V. las entradas de nuestro blog del 6 y 7 de abril de 2020 sobre el Real Decreto-Ley $\mathrm{N}^{\circ} 11 / 2020$, de medidas urgentes complementarias en el ámbito social y económico para hacer frente al COVID-19”.
} 
Seguridad Social y tributarias para paliar los efectos del COVID-19 (RDL 19/2020) cuya disposición final octava modificó el art.40, apartados 3 y 5, del RDL 8/2020.

Además de la normativa española, hay que tener en cuenta la publicación, del Reglamento (UE) 2020/699 del Consejo de 25 de mayo de 2020 de medidas temporales relativas a la junta general de las sociedades europeas (SE) y la asamblea general de las sociedades cooperativas europeas $(S C E)^{19}$.

\section{B) Normativa extraordinaria sobre los órganos de gobierno de las sociedades mercantiles en general}

Esta normativa extraordinaria afecta a los aspectos siguientes:

\section{La convocatoria y la celebración de la junta general}

Las medidas extraordinarias permiten el órgano de administración modificar el lugar y la hora previstos para la celebración de la junta o revocar el acuerdo de convocatoria, si la convocatoria de la junta general se hubiera publicado antes de la declaración del estado de alarma pero el día de celebración fuera posterior a esa declaración, mediante anuncio publicado con una antelación mínima de cuarenta y ocho horas en la página web de la sociedad y, si la sociedad no tuviera página web, en el BOE.

\section{Las sesiones de los órganos de gobierno de las sociedades mercantiles}

Las sesiones de los órganos de gobierno de las sociedades mercantiles han resultado afectadas por tres tipos de medidas extraordinarias que merecen este adjetivo por dos razones: temporal, ya que estarán vigentes durante el periodo de alarma y normativo puesto que serán aplicables, aunque los estatutos no lo hubieran previsto.

Estas medidas se refieren:

a) Primero, a su ámbito de aplicación subjetivo, porque abarcan a los órganos de gobierno y de administración de las sociedades mercantiles, incluyendo las comisiones delegadas y las demás comisiones obligatorias o voluntarias que tuvieran constituidas.

b) Segundo, a su ámbito de aplicación objetivo, porque abarcan a las sesiones de los órganos de gobierno y de administración y los medios de celebración por videoconferencia o por conferencia telefónica múltiple.

c) Tercero, a sus garantías, ya que su aplicación se condiciona a que "todos los miembros del órgano dispongan de los medios necesarios y a que el secretario del órgano reconozca su identidad, y así lo exprese en el acta, que remitirá de inmediato a las direcciones de correo electrónico de cada uno de los concurrentes" (art. 40.1 RDL 8/2020).

${ }_{19}$ DOUE de 27 de mayo de 2020 (págs. L 165/25 y ss.). 


\section{Los acuerdos de los órganos de gobierno de las sociedades mercantiles}

Los acuerdos de los órganos de gobierno podrán adoptarse mediante votación por escrito y sin sesión; dejando la decisión de hacerlo de este modo en manos del presidente, quien estará obligando a ello cuando así cuando lo soliciten, al menos, dos de los miembros del órgano (art. 40.2 RDL 8/2020). Este apartado 2 del art. 40 del RDL $8 / 2020$, tras su modificación por el RDL 11/2020 saca las consecuencias naturales de las medidas extraordinarias precedentes a los acuerdos cuando admite que "aunque los estatutos no lo hubieran previsto, durante el periodo de alarma, los acuerdos de los órganos de gobierno y de administración (...) podrán adoptarse mediante votación por escrito y sin sesión"; dejando la decisión de hacerlo de este modo en manos del presidente y deberán adoptarse así cuando lo solicite, al menos, dos de los miembros del órgano. Se realiza la misma extensión de la medida a las comisiones delegadas y a las demás comisiones obligatorias o voluntarias que tuviera constituidas de sociedad, la misma ficción de que la sesión se entenderá celebrada en el domicilio social y se añade la referencia al hecho de que resultará aplicable a todos estos acuerdos lo establecido en el art. 100 del Reglamento del Registro Mercantil, incluso aunque no se trate de sociedades mercantiles.

\section{C) Normativa extraordinaria sobre los órganos de gobierno de las sociedades anónimas cotizadas}

\section{Juntas generales}

La convocatoria y la celebración mediante asistencia por medios telemáticos y el voto a distancia en la junta general de accionistas de las sociedades cotizadas se acomoda a los criterios siguientes: Flexibilidad para-estatutaria; auto-regulación; garantías de identidad en cuanto al ejercicio del derecho de los derechos de asistencia, de información y de voto; y ficción de ubicación en el domicilio social con independencia de donde se halle el Presidente de la Junta, por audioconferencia o videoconferencia (art. 41.1.c) u d) RDL 8/2020).

El plazo máximo de celebración de la junta general ordinaria de accionistas de las sociedades cotizadas se prorroga hasta los diez primeros meses del ejercicio social (art. 41.1.b) RDL 8/2020) ${ }^{20}$.

\section{Consejos de Administración}

Los acuerdos del Consejo de Administración y de la Comisión de Auditoría de sociedades cotizadas adoptados por videoconferencia o por conferencia telefónica múltiple serán válidos, aunque esta posibilidad no esté contemplada en los estatutos sociales, siempre que todos los consejeros dispongan de los medios necesarios para ello, y el Secretario reconozca su identidad (art. 41.2 RDL 8/2020).

\footnotetext{
${ }^{20}$ V. la entrada de nuestro blog financiero (ajtapia.com) de 07.05.2020 sobre "Juntas generales de accionistas de las sociedades cotizadas. Convocatoria y celebración por medios telemáticos".
} 


\section{D) Normativa extraordinaria sobre las cuentas de las sociedades mercantiles}

\section{El proceso de elaboración de las cuentas}

Las medidas extraordinarias afectan a las tres fases de elaboración de las cuentas:

a) Primero, se suspendió el inicio del cómputo del pazo de tres meses para su formulación por los administradores hasta que finalice el estado de alarma, reanudándose de nuevo por otros tres meses a contar desde esa fecha (art. 40.3 RDL 8/2020).

b) Segundo, se prorrogó por dos meses - que se deberán contar a contar desde que finalizó el estado de alarma- el plazo para la verificación contable de las cuentas, tanto si la auditoría fuera obligatoria como voluntaria (art. 40.4 RDL 8/2020).

c) Tercero, se posponen a los dos meses siguientes a contar desde que finalice el plazo para formular las cuentas anuales por los administradores - previamente suspendido durante el estado de alarma- el deber de celebrar la junta general ordinaria para aprobar las cuentas del ejercicio (art. 40.5 y 6 RDL 8/2020). En particular, los apartados 5, 6 Y 6 bis del art. 40 del RDL 8/2020, tras sus modificaciones sucesivas por el RDL 11/2020 y por el RDL 19/2020, establecen las tres previsiones siguientes:

c.1) Posponen a los dos meses siguientes a contar desde que finalice el plazo para formular las cuentas anuales por los administradores - previamente suspendido durante el estado de alarma- el deber de celebrar la junta general ordinaria para aprobar las cuentas del ejercicio. En particular, con la reforma introducida por la DF $8^{\mathrm{a}}$, ap. Cuatro del RDL 19/2020 que reduce de tres a dos meses el plazo para aprobar las cuentas anuales desde la formulación, con lo que se armoniza dicho plazo para todas las sociedades, sean o no cotizadas. Se afirma que así todas deberán tener las cuentas aprobadas dentro de los diez primeros meses del ejercicio.

c.2) Permiten el órgano de administración modificar el lugar y la hora previstos para la celebración de la junta o revocar el acuerdo de convocatoria ${ }^{21}$, si la convocatoria de la junta general se hubiera publicado antes de la declaración del estado de alarma pero el día de celebración fuera posterior a esa declaración, mediante anuncio publicado con una antelación mínima de cuarenta y ocho horas en la página web de la sociedad y, si la sociedad no tuviera página web, en el BOE.

c.3) Autorizan al órgano de administración a sustituir la propuesta de aplicación del resultado contenida en la memoria por otra propuesta, en el caso de que se hubiera formulado ya las cuentas anuales; exigiendo que dicho órgano de administración justifique dicha sustitución en base a la situación creada por el COVID-19 y la acompañe de un escrito del auditor de cuentas en el que este indique que no habría modificado su opinión de auditoría si hubiera conocido en el momento de su firma la nueva pro-

\footnotetext{
21 Se establece que "en caso de revocación del acuerdo de convocatoria, el órgano de administración deberá proceder a nueva convocatoria dentro del mes siguiente a la fecha en que hubiera finalizado el estado de alarma".
} 
puesta $^{22}$. La decisión del órgano de administración deberá publicarse antes de la celebración de la junta general ya convocada y la nueva propuesta aplicación del resultado deberá cumplir los requisitos de justificación y escrito de auditor de cuentas ${ }^{23}$.

\section{La propuesta de aplicación del resultado}

Para las sociedades anónimas de régimen común, se autoriza al órgano de administración a sustituir la propuesta de aplicación del resultado contenida en la memoria por otra propuesta, en el caso de que se hubiera formulado ya las cuentas anuales; exigiendo que dicho órgano de administración justifique dicha sustitución en base a la situación creada por el COVID-19 y la acompañe de un escrito del auditor de cuentas en el que este indique que no habría modificado su opinión de auditoría si hubiera conocido en el momento de su firma la nueva propuesta (art. 40.6 bis RDL 8/2020). En el caso de las sociedades anónimas cotizadas, se añade un plus de transparencia al ejercicio de esta facultad (art. 41.3 RDL 8/2020).

\section{La información financiera periódica de las sociedades cotizadas}

Se prorroga el plazo de cumplimiento de la obligación de los administradores de sociedades cotizadas de publicar y remitir su informe financiero anual a la CNMV y el informe de auditoría de sus cuentas anuales desde los de tres meses normales hasta seis meses contados a partir del cierre de ejercicio social; plazo que se extenderá a cuatro meses para la publicación de la declaración intermedia de gestión y el informe financiero semestral (art. 41.1.a RDL 8/2020).

\section{E) Otras medidas extraordinarias que repercuten en el Derecho societario}

\section{La suspensión del ejercicio del derecho de separación en las sociedades de capital}

En circunstancias normales, la separación de socios se regula en el art. 346 y siguientes de la LSC que comienza enumerando las "causas legales de separación": sustitución o modificación sustancial del objeto social, prórroga de la sociedad, reactivación de la sociedad, creación modificación o extinción anticipada de la obligación de realizar prestaciones accesorias, transformación o traslado de domicilio al extranjero.

\footnotetext{
${ }^{22}$ El apartado 6 bis añade: "Tratándose de sociedades cuya junta general ordinaria estuviera convocada, el órgano de administración podrá retirar del orden del día la propuesta de aplicación del resultado a efectos de someter una nueva propuesta a la aprobación de una junta general que deberá celebrarse también dentro del plazo legalmente previsto para la celebración de la junta general ordinaria".

23 El apartado 6 bis añade: "La certificación del órgano de administración a efectos del depósito de cuentas se limitará, en su caso, a la aprobación de las cuentas anuales, presentándose posteriormente en el Registro Mercantil certificación complementaria relativa a la aprobación de la propuesta de aplicación del resultado".
} 
En las circunstancias extraordinarias por la crisis del COVID-19, el apartado 8 del art. 40 del RDL 8/2020, tras su modificación por el RDL 11/2020, suspende el derecho de separación de los socios hasta que finalice el estado de alarma y las prórrogas del mismo que, en su caso, se acuerde.

Procede añadir que, según el art. 5 RDL 18/2020, las sociedades mercantiles que se acojan a los expedientes de regulación temporal de empleo regulados en el art. 1 y que utilicen los recursos públicos destinados a los mismos, no podrán proceder al reparto de dividendos correspondientes al ejercicio fiscal en que se apliquen estos expedientes de regulación temporal de empleo, excepto si abonan previamente el importe correspondiente a la exoneración aplicada a las cuotas de la seguridad social. Y añade que no se tendrá en cuenta el ejercicio en el que la sociedad no distribuya dividendos en aplicación de lo establecido en este artículo, a los efectos del ejercicio del derecho de separación de los socios previsto en el apartado 1 del art. 348 bis del TRLSC. Esta limitación al reparto de dividendos no es de aplicación para aquellas entidades que, a fecha de 29 de febrero de 2020, tuvieran menos de cincuenta personas trabajadoras, o asimiladas a las mismas, en situación de alta en la Seguridad Social.

\section{La suspensión del reintegro de las aportaciones en las sociedades cooperativas}

En las circunstancias extraordinarias de la crisis del COVID-19, el apartado 9 del art. 40 del RDL 8/2020, tras su modificación por el RDL 11/2020, dispone: "El reintegro de las aportaciones a los socios cooperativos que causen baja durante la vigencia del estado de alarma queda prorrogado hasta que transcurran seis meses a contar desde que finalice el estado de alarma".

\section{SUPERVIVENCIA EMPRESARIAL EN ESPAÑA EN ÉPOCA DEL COVID-19}

\section{A) La normativa extraordinaria promulgada en España para facilitar la supervivencia empresarial en época del COVID-19: doble alcance funcional y estructural}

La pandemia del COVID-19 ha afectado directamente a la propia supervivencia o viabilidad de las empresas y, por ello, se ha promulgado una panoplia de instrumentos que integran la normativa extraordinaria para facilitar la supervivencia empresarial en época del COVID-19. Y, dado que la mayor parte de las empresas adoptan el ropaje jurídico de sociedades mercantiles de capital, estas normas inciden preferentemente en el Derecho de sociedades mercantiles. En particular, podemos clasificar estos instrumentos normativos en dos categorías ${ }^{24}$ : funcional y estructural.

\footnotetext{
${ }^{24}$ El lector interesado puede consultar el Capítulo 15 de nuestra "Guía Concursal", Ed. Thomson Reuters Aranzadi, 2020, pp. 197 y ss. sobre las "Medidas extraordinarias concursales adoptadas para hacer frente al impacto del COVID-19".
} 


\section{B) Normativa extraordinaria funcional: las medidas concursales y societarias}

Calificamos de normativa extraordinaria funcional para facilitar la supervivencia empresarial en época del COVID-19 la que no altera el marco de sujetos que operan en el mercado societario, sino que les permite adaptar su conducta al entorno hostil que plantea la pandemia.

En este punto, destacan las medidas concursales y societarias de la Ley $\mathrm{N}^{\circ} 3 / 2020$, de 18 de septiembre como continuación de las establecidas en el Real Decreto-Ley $\mathrm{N}^{\circ}$ 16/2020, de 28 de abril ${ }^{25}$. En efecto, en el BOE núm. 250, del sábado 19 de septiembre de 2020, se publicó la Ley $N^{\circ} 3 / 2020$, de 18 de septiembre, de medidas procesales y organizativas para hacer frente al COVID-19 en el ámbito de la Administración de Justicia que, en su Capítulo II (arts. 3 a 13) incluye una serie de medidas en el ámbito concursal y societario que pretenden seguir ayudando a la supervivencia empresarial en medio de la profunda crisis económica derivada de la pandemia del COVID. Estas medidas reproducen, en gran parte, las normas extraordinarias concursales adoptadas para hacer frente al impacto del COVID-19 que estableció el Capítulo II (arts. 8 a 18) del Real Decreto-Ley N $\mathrm{N}^{\circ}$ 16/2020, de 28 de abril, de medidas procesales y organizativas para hacer frente al COVID-19 en el ámbito de la Administración de Justicia, convalidado por Acuerdo de 13 de mayo de 2020, publicado en el BOE de 15 de mayo ${ }^{26}$.

Según decimos, el principio general que inspira las medidas concursales y societarias establecidas en el Capítulo II (arts. 3 a 13) de la Ley $N^{\circ}$ 3/2020 -al igual que sucedía con las del Capítulo II (arts. 8 a 18) del Real Decreto-Ley $N^{\circ} 16 / 2020$, de 28 de abriles la supervivencia de las empresas viables como así consta en el apartado II de su Preámbulo cuando dice:

"Se trata, en definitiva, de evitar declaraciones de concurso o apertura de la fase de liquidación respecto de empresas que pueden ser viables en condiciones generales de mercado (valor en funcionamiento superior al valor de liquidación), con la consiguiente destrucción de tejido productivo y de puestos de trabajo".

En todo caso, ello no hace más que proyectar la finalidad general de la normativa concursal en este periodo de crisis pandémica ${ }^{27}$.

\footnotetext{
25 El lector interesado en profundizar en esta normativa excepcional puede consultar las dos entradas publicadas los días 6 y 7 de octubre de 2020 en nuestro blog financiero (ajtapia.com) sobre el "Salvamento empresarial: Las nuevas medidas concursales y societarias establecidas en la Ley $\mathrm{N}^{\circ} 3 / 2020$, de 18 de septiembre, para hacer frente al COVID-19".

${ }^{26}$ El lector interesado en profundizar en esta normativa excepcional puede consultar la entrada publicada el día 4 de mayo de 2020 en nuestro blog financiero (ajtapia.com) sobre el "Impacto del Real Decreto-Ley N 16/2020 en la normativa mercantil y en el sistema financiero (1). Concurso de acreedores y reformas societarias".

27 En este sentido, hemos destacado -en nuestra "Guía Concursal" (Ed. Thomson Reuters Aranzadi, 2020, p. 31)- que el TRLC enuncia, con más claridad si cabe que el texto original de la LC, la tesis conservacionista de la empresa que inspira todo su contenido. Así lo anuncia el decimocuarto y último párrafo del epígrafe II del preámbulo -innominado- del TRLC cuando nos dice: "El Derecho concursal se reivindica como una herramienta fundamental para la conservación de tejido empresarial y empleo; y de ello es consciente el legislador y la propia Unión Europea que ha desarrollado una importante iniciativa normativa a través de Directivas como la mencionada inmediatamente antes. Esta finalidad conservativa del Derecho concursal se manifiesta no solo a través de normas con vocación de permanencia como el presente
} 
Las medidas concursales y societarias implantadas por la Ley $\mathrm{N}^{\circ} 3 / 2020$ impactan en las siguientes fases de la regulación del concurso ${ }^{28}$ :

a) La fase pre-concursal, donde se incluyen las medidas de la Ley $\mathrm{N}^{\circ}$ 3/2020 referidas a los acuerdos extrajudiciales de pagos y a los acuerdos de refinanciación.

b) La fase concursal común, donde se incluyen las medidas de la Ley $\mathrm{N}^{\circ} 3 / 2020$ referidas a la moratoria en el deber de solicitar la declaración de concurso; los incentivos de la financiación de las empresas mediante la recalificación de determinados créditos, con la calificación de los créditos derivados de compromisos de financiación como créditos contra la masa y la calificación de los créditos derivados de ingresos de tesorería en concepto de préstamos, créditos u otros negocios análogos concedidos al deudor por personas especialmente relacionadas como créditos ordinarios; y las que afectan a la Impugnación del inventario y de la lista de acreedores

c) La fase de las soluciones al concurso, donde se incluyen las medidas de la Ley $\mathrm{N}^{\circ}$ 3/2020 referidas a la fase concursal del convenio con la posible modificación del convenio concursal; y a la fase concursal de la liquidación con el aplazamiento del deber de solicitar la apertura de la fase de liquidación, la aprobación del plan de liquidación y la enajenación de la masa activa.

Las medidas concursales y societarias implantadas por la Ley $\mathrm{N}^{\circ} 3 / 2020$ se completan con las medidas concursales de la Ley $\mathrm{N}^{\circ} 3 / 2020$ referidas a la agilización del proceso concursal que establece, en concreto, su art. 9 -en línea con el art. 14 del RDL 16/2020 - que dispone la "Tramitación preferente" de determinados incidentes y actuaciones concursales hasta el 14 de marzo de 2021; y as reformas societarias que introduce la Ley $\mathrm{N}^{\circ} 3 / 2020$ en el régimen de la causa legal de disolución por pérdidas relacionadas con la crisis del COVID-19.

\section{C) Normativa extraordinaria estructural o institucional: el Fondo Apoyo a la Solvencia de Empresas Estratégicas (FASEE)}

Calificamos de normativa extraordinaria estructural o institucional para facilitar la supervivencia empresarial en época del COVID-19 a la que crea nuevas entidades o instituciones para facilitar aquella supervivencia de las empresas viables. Dentro de esta normativa destaca la que establece el Fondo Apoyo a la Solvencia de Empresas Estratégicas $\left(\right.$ FASEE) ${ }^{29}$ que se crea por el art. 2 del Real Decreto-Ley N ${ }^{\circ}$ 25/2020,

texto refundido (...)". Esta tesis conservacionista de la empresa también inspira -con mayor intensidad, si cabe- las medidas extraordinarias concursales adoptadas para hacer frente al impacto del COVID-19 que estableció el Capítulo II (arts. 8 a 18) del Real Decreto-Ley $\mathrm{N}^{\circ}$ 16/2020, de 28 de abril, de medidas procesales y organizativas para hacer frente al COVID-19 en el ámbito de la Administración de Justicia. Sobre la "justificación y antecedentes de las reformas de la normativa concursal por el RDL 16/2020" el lector interesado puede consultar nuestra "Guía Concursal” citada, pág.199 y ss.

28 Seguimos la estructura lógica y cronológica del Capítulo 15 de nuestra "Guía Concursal” (Ed. Thomson Reuters Aranzadi, 2020, p.197 y ss., a la que nos remitimos, para evitar reiteraciones innecesarias.

${ }^{29}$ El lector interesado en profundizar en la regulación de este FASEE podrá ver nuestros estudios sobre "El 
de 3 de julio, de medidas urgentes para apoyar la reactivación económica y el empleo con el objetivo de compensar el impacto de la emergencia sanitaria en el balance de empresas solventes consideradas estratégicas para el tejido productivo y económico. El FASEE es un fondo carente de personalidad jurídica del sector público estatal, adscrito a la Administración General del Estado, a través del Ministerio de Hacienda. De su régimen, conviene destacar los aspectos siguientes:

\section{La estructura del FASEE}

La estructura del FASEE responde al esquema común a los fondos de inversión que son patrimonios sin personalidad jurídica que requieren satisfacer dos necesidades básicas que son su gestión, que ejerce su Consejo Gestor; y su custodia, a cargo de la SEPI.

El elenco de sujetos que integran la estructura subjetiva del FASEE se completa con las empresas beneficiarias de las ayudas del FASEE que deberán reunir dos cualidades generales: Atravesar severas dificultades de carácter temporal a consecuencia de la pandemia del COVID-19 y ser

“empresas consideradas estratégicas para el tejido productivo nacional o regional, entre otros motivos, por su sensible impacto social y económico, su relevancia para la seguridad, la salud de las personas, las infraestructuras, las comunicaciones o su contribución al buen funcionamiento de los mercados".

En particular, las empresas beneficiarias de las ayudas del FASEE deberán reunir una serie de criterios de elegibilidad que podemos ordenar en 5 categorías: los "criterios de elegibilidad de las empresas beneficiarias" que podemos ordenar en 5 categorías: Condiciones positivas ciertas o actuales ${ }^{30}$, condiciones positivas potenciales o hipotéticas $^{31}$, condiciones negativas ciertas o actuales que integran una especie de "cer-

Fondo de Apoyo a la Solvencia de Empresas Estratégicas (FASEE) como instrumento de salvamento contra la pandemia del COVID 19" de inminente publicación en el número 160 de la Revista de Derecho Bancario y Bursátil y en el número 60 de la Revista Iberoamericana de Mercados de Valores.

30 Entre las que están "constituir una empresa no financiera con domicilio social y principales centros de trabajo situados en España"; "hallarse al corriente de pago de obligaciones por reintegro de subvenciones o ayudas públicas"; y "hallarse al corriente a 31 de diciembre de 2019 en el cumplimiento de las obligaciones tributarias o frente a la Seguridad Social impuestas por las disposiciones vigentes". El Acuerdo establece una previsión estratégicamente esencial-por la propia discrecionalidad implícita en los conceptos jurídica y económicamente indeterminados que se utilizan-cuando añade que "adicionalmente, la decisión de utilización del Fondo atenderá, entre otros elementos, a la importancia sistémica o estratégica del sector de actividad o de la empresa, por su relación con la salud y la seguridad pública o su carácter tractor sobre el conjunto de la economía, su naturaleza innovadora, el carácter esencial de los servicios que presta o su papel en la consecución de los objetivos de medio plazo en el ámbito de la transición ecológica, la digitalización, el aumento de la productividad y el capital humano".

31 Entre las que están "demostrar su viabilidad a medio y largo plazo, presentando a tal efecto en su solicitud un Plan de Viabilidad para superar su situación de crisis, describiendo la utilización proyectada del apoyo público solicitado con cargo al Fondo, los riesgos medioambientales, las previsiones para afrontarlos y su estrategia energética" y "presentar una previsión de reembolso del apoyo estatal con un calendario de amortización de la inversión nominal del Estado y de abono de las remuneraciones y las medidas que se adoptarían para garantizar el cumplimiento del plan de reembolso del apoyo estatal”. 
tificado de buena conducta" ${ }^{\prime 32}$, condiciones negativas potenciales o hipotéticas, que integran una especie de "certificado de estado de necesidad" ${ }^{33} \mathrm{y}$ condiciones neutras ${ }^{34}$.

Las empresas beneficiarias del FASEE deberán adoptar los acuerdos sociales o, en su caso, las modificaciones estatutarias que aseguren el cumplimiento de tres tipos de restricciones en su actuación que son: restricciones competenciales; restricciones de dividendos a sus socios y restricciones de remuneración a sus administradores.

La estructura objetiva del FASEE se integra por su patrimonio que tendrá una dotación inicial de 10.000 millones de euros para la toma de instrumentos financieros, incluyendo deuda, instrumentos híbridos o participaciones en el capital social de las empresas. empresas que atraviesan severas dificultades de carácter temporal a consecuencia de la pandemia del COVID-19.

\section{El funcionamiento del FASEE}

El funcionamiento del FASEE se traducirá en las ayudas en forma de recapitalización que tendrán como objetivo dar respuesta a aquellas situaciones en las que el crédito o las medidas de liquidez no fuesen suficientes para asegurar el mantenimiento de la actividad de empresas.

La estructura contractual de soporte de las ayudas del FASEE se apoyará en los Acuerdos entre el FASEE y las compañías beneficiarias que serán el Acuerdo de Apoyo Financiero Público Temporal y el Acuerdo de Accionistas o el Acuerdo de Gestión con la Compañía.

Las operaciones de apoyo público temporal para reforzar la solvencia empresarial, financiadas con cargo al FASEE podrán tomar forma de instrumentos financieros de tres tipos, dos de forma principal y otros de forma complementaria: De forma principal, en instrumentos financieros puros de capital como la suscripción de acciones o participaciones sociales o cualquier otro instrumento de capital; y en instrumentos

\footnotetext{
32 Entre las que están "no constituir una empresa en crisis a 31 de diciembre de 2019, en los términos establecidos por el artículo 2 (18) del Reglamento de la Comisión (UE) n. ${ }^{\circ}$ 651/2014 (...)"; "no haber solicitado la declaración de concurso voluntario, haber sido declarados insolventes en cualquier procedimiento, hallarse declarados en concurso (...)" con algunas salvedades; "no haber sido condenada mediante sentencia firme a la pena de pérdida de la posibilidad de obtener subvenciones o ayudas públicas o por delitos de prevaricación, cohecho, malversación de caudales públicos, tráfico de influencias, fraudes y exacciones ilegales o delitos urbanísticos"; y "no haber dado lugar, por causa de la que hubiese sido declarada culpable, a la resolución firme de cualquier contrato celebrado con la Administración".

${ }^{33}$ Entre las que están las consistentes en que, "en ausencia de apoyo público temporal recibido con cargo al Fondo, el beneficiario cesaría en su actividad o tendría graves dificultades para mantenerse en funcionamiento. Estas dificultades podrán demostrarse por el deterioro, en particular, del coeficiente deuda/ capital del beneficiario o por indicadores similares"; y "justificar que un cese forzoso de actividad tendría un elevado impacto negativo sobre la actividad económica o el empleo, a nivel nacional o regional. La apreciación del impacto económico y sobre el empleo, directo e indirecto, se medirá en relación con la situación de la empresa al cierre del ejercicio 2019".

${ }^{34}$ Entre las que está la de "informar del conjunto de medidas de apoyo público de las que se haya beneficiado en los últimos diez años, con indicación de la cuantía, concepto y órgano otorgante de la subvención pública o ayuda bajo cualquier modalidad".
} 
financieros híbridos de capital, en forma de concesión de préstamos participativos o deuda convertible; y, de manera complementaria, las operaciones de apoyo público temporal para reforzar la solvencia también podrán materializarse a través de cualesquiera otras facilidades crediticias.

Las operaciones financiadas con cargo al FASEE se moverán en una horquilla que irá desde un importe mínimo de 25 millones de euros por beneficiario, salvo casos excepcionales debidamente justificados; hasta un importe máximo no determinado "a priori" sino determinable en cada caso en función del mínimo necesario para restaurar la viabilidad de la empresa.

El correspondiente Acuerdo de Apoyo Financiero Público Temporal establecerá los niveles de remuneración, así como los calendarios de pagos, de los instrumentos de intervención del FASEE que se adaptarán al tipo de instrumento financiero.

Se regulan dos aspectos de la salida del FASEE de las empresas beneficiarias mediante el reembolso de la participación del Estado que son el momento y el precio.

El impacto de las ayudas del FASEE en la competencia empresarial se controla mediante las restricciones a las que estará sujeta la empresa beneficiada hasta el reembolso definitivo del apoyo público temporal recibido con cargo al FASEE.

El origen público de los recursos del FASEE exige adoptar cautelas especiales en los dos sentidos siguientes: La transparencia, que afecta a las dos partes de la relación jurídica nacida de la intervención del FASEE; y el seguimiento de las operaciones que se realizará a nivel nacional a nivel de la UE.

La compatibilidad del FASEE con la normativa de la UE sobre ayudas estatales por el COVID-19 se proyecta en tres características de sus ayudas: Se trata de una medida de intervención de último recurso, tiene carácter temporal y las operaciones con cargo al FASEE se llevarán a cabo previa solicitud por parte de la empresa interesada.

La propia finalidad de interés público del FASEE justifica que goce de determinados privilegios en forma de exenciones normativas tributarias y mercantiles, en materia de gobierno corporativo y en el mercado de control societario, al estar liberado del deber de formular una OPA.

El interés público implícito en la actuación del FASEE justifica una “disposición antitransparencia" porque los datos, documentos e informaciones que obren en poder del Consejo Gestor del FASEE y de SEPI en virtud de las funciones que le encomienda la ley tendrán carácter reservado. 
